Conclusions Epoprostenol as the sole anti-haemostatic agent for CRRT increases mean filter life, decreases bleeding risk without increasing risk of hypotension, platelet transfusion or mortality.

\section{0-202 PHTHALATE EXPOSURE AND CHILD DEVELOPMENT: THE POLISH MOTHER AND CHILD COHORT STUDY}

${ }^{1} \mathrm{~K}$ Polanska, ${ }^{2} \mathrm{D}$ Ligocka, ${ }^{1} \mathrm{~W}$ Sobala, ${ }^{1} \mathrm{~W}$ Hanke. 'Department of Environmental Epidemiology, Nofer Institute of Occupational Medicine, Lodz, Poland; ${ }^{2}$ Department of Toxicology and Carcinogenesis, Nofer Institute of Occupational Medicine, Lodz, Poland

\subsection{6/archdischild-2014-307384.270}

Background Widespread phthalate exposure has prompted investigations concerning their potential adverse health effects. The objective of this study was to evaluate the impact of pre and early postnatal phthalate exposure on child psychomotor development basing on the data from the prospective Polish Mother and Child Cohort Study (REPRO PL).

Methods Phthalate exposure was determined by measuring 11 phthalate metabolites (MEP, MiBP, MnBP, 3OH-MnBP, MBzP, MEHP, 5OH-MEHP, 5oxo-MEHP, 7OH-MiNP, 7oxo-MiNP, $\mathrm{MnOP})$ in the urine collected from mothers during the third trimester of pregnancy (prenatal exposure) and from their children at 24 th month of age (postnatal exposure). The analysis was performed by HPLC-MS/MS method. Child psychomotor development was assessed at the 2 nd year of age by Bayley Scales of Infant and Toddler Development.

Results Child motor development was inversely associated with natural $\log$ concentrations $(\mu \mathrm{g} / \mathrm{g}$ creatinine) of $3 \mathrm{OH}-\mathrm{MnBP}(\beta=-$ $2.3 ; 95 \%$ CI -4.0 to -0.6$)$, 5OH-MEHP $(\beta=-1.2 ; 95 \%$ CI -2.2 to -0.3$)$, 5oxo-MEHP $(\beta=-1.8 ; 95 \%$ CI -330 to -0.2$)$ and DEHP metabolites $(\beta=-2.2 ; 95 \%$ CI -3.60 to -0.8$)$ and sum of high molecular weight phthalates $(\beta=-2.5 ; 95 \%$ CI -4.1 to -0.9$)$ in the urine collected from mothers during pregnancy after adjustment for variety of potential confounders. Additional adjustment for postnatal phthalate exposure did not change the results. Postnatal child exposure to phthalates was not associated with any of the measured scores of child psychomotor development.

Conclusions The study findings add further support to the possibility that prenatal phthalate exposure may be detrimental to child neurodevelopment and underscore the importance of policies and public health interventions to reduce such exposure.

\section{0-203 TRIPLE-BLIND, RANDOMISED CONTROLLED TRIAL ON THE USE OF FENUGREEK (TRIGONELLA FOENUM-GRAECUM L.) FOR AUGMENTATION OF BREASTMILK VOLUME AMONG POSTPARTUM MOTHERS}

C Brillante, JB Mantaring. Pediatrics, Manila Doctors Hospital, Manila, Philippines

\subsection{6/archdischild-2014-307384.271}

Objective To determine the efficacy of Fenugreek supplementation on the breastmilk production of mothers on postpartum days 1 to 5 .

Methods Postpartum mothers aged 18 years and above at a tertiary private hospital were eligible to participate in this randomised, triple-blind, placebo-controlled study. Randomization was computer-generated and allocation was concealed. Mothers were randomised to receive 9 capsules of $610 \mathrm{mg}$ Fenugreek seeds or placebo and were instructed to take 3 capsules, 3 times per day for 5 days. Mothers recorded the time and volume of expressed breastmilk. The contents of the capsules were unknown to the investigator, participants and study personnel. Statistical analyses used were T-test and Chi-square. A p-value of $<0.05$ was considered significant.

Results Sixty mothers were randomised to receive Fenugreek (n $=30$ ) or placebo $(n=30)$. Twenty-four were excluded due to non-compliance leaving 36 mothers included in the analysis. There is a significant difference in the mean volume production $(\mathrm{ml} / \mathrm{hr}$ ) in favour of the Fenugreek group on days 1 to 5 (Day1: $9.49 \pm 5.43$ vs $5.23 \pm 5.48, \mathrm{p}=0.0125$; Day5: $25.06 \pm 12.61$ vs $13.78 \pm 8.57, \mathrm{p}=0.0046)$. Side effects noted are maple-like smell of urine, breast tenderness, hunger and headache but none reported any serious adverse event. Respondents were satisfied to extremely satisfied with the intake of study intervention.

Conclusion Fenugreek significantly increases the breastmilk volume produced by mothers on post-partum days 1 to 5 compared to placebo. There were no reported serious adverse events in both groups. Overall, mothers are satisfied with the intake of Fenugreek.

\section{0-203a INHALED MAGNESIUM FOR MODERATE AND SEVERE PAEDIATRIC ASTHMA}

H Abu Rasheed, K Al-Ansari. Division of Pediatric Emergency Medicine Department of Pediatrics, Hamad Medical Corporation, Doha, Qatar

\subsection{6/archdischild-2014-307384.272}

Background Intravenous magnesium sulfate, a rescue therapy added to combined bronchodilator and systemic steroid therapy for moderate and severe asthma, is uncommonly administered. We hypothesised that nebulized magnesium sulfate would confer benefit without undue risk.

Methods Patients aged 2 to $14 \mathrm{y}$ with moderate and severe status asthmaticus (PRAM severity score $>4$ ) admitted to infirmary care were randomised double-blind to $800 \mathrm{mg}$ nebulized magnesium sulfate or normal saline placebo via Aeroneb Pro and Idehaler, after intensive therapy with combined albuterol-ipratropium and intravenous methylprednisolone. Time to medical readiness for discharge was the primary outcome; sample size was chosen to detect a $10 \%$ improvement. Improvement over time in PRAM severity score and other secondary outcomes were compared for the overall group and severe asthma subset.

Results 191 magnesium sulfate and 174 placebo patients met criteria for analysis. The groups were similar with mean baseline PRAM scores $>7$. Blinded active therapy significantly increased blood magnesium level 2 h post-treatment 0.85 (SD 0.07) vs 0.82

12-point Pediatric Respiratory Assessment Measure (PRAM) Score

\begin{tabular}{|c|c|c|c|c|}
\hline \multirow[b]{2}{*}{$\underline{\text { Sign }}$} & \multicolumn{4}{|c|}{ Scoring } \\
\hline & $\underline{0}$ & $\underline{1}$ & $\underline{2}$ & $\underline{\mathbf{3}}$ \\
\hline $\begin{array}{c}\text { Suprastemal } \\
\text { retractions }\end{array}$ & None & & Present & \\
\hline $\begin{array}{l}\text { Scalene muscle } \\
\text { activity }\end{array}$ & None & & Present & \\
\hline Air entry & Normal & $\begin{array}{l}\text { Decreased at } \\
\text { bases }\end{array}$ & $\begin{array}{l}\text { Diffusely } \\
\text { decreased }\end{array}$ & Minimal or absent \\
\hline Wheezing* & None & $\begin{array}{l}\text { Expiratory } \\
\text { only }\end{array}$ & $\begin{array}{l}\text { Inspiratory and } \\
\text { expiratory }\end{array}$ & $\begin{array}{l}\text { Audible without } \\
\text { stethoscope or } \\
\text { silent chest with } \\
\text { minimal air entry }\end{array}$ \\
\hline $\begin{array}{l}\text { Pulse oxygen } \\
\text { saturation }\end{array}$ & $\begin{array}{l}95 \% \text { or } \\
\text { higher }\end{array}$ & $92-94 \%$ & $<92 \%$ & \\
\hline
\end{tabular}

Abstract 0-203a Figure 1 